\title{
IS THE INTERNET DISGUISED AS A PERPETRATOR: A STUDY ON THE CYBER CRIMES AGAINST WOMEN IN INDIA
}

\author{
Swasati Handique \\ Master's in Social Work Counselling, Tata Institute of Social Sciences, Guwahati, Assam, India \\ DOI: 10.46609/IJSSER.2020.v05i07.021 URL: https://doi.org/10.46609/IJSSER.2020.v05i07.021
}

\begin{abstract}
Violence against women is a violation of human rights and not another marvel in India. It has been continuing since time immemorial but only in different shapes and way from time to time in Indian history. The advancement of technology and updated versions of the internet has created new ways of cyber crimes and the women are mostly at the target of these crimes. Most of the cyber crimes take place against women who can be easily exploited. Due to lack of evidences and fear of defamation, identifying criminal is very hard which makes the violators to get away with their crimes. Cyber crime, lately have been emerging as a major challenge that the law enforcement agencies are facing in the country with women and children being at risk of it. According to recent studies, many underage girls and other female victims have committed suicide after their private photographs and information were being released over the internet. The paper puts forward the various crimes that the women in India are subjected to and argues on how the government has failed to match up with the security that is currently needed for the women in the country. It highlights how the spike in cyber crimes has been affecting the women and how it is impacting in their social life.
\end{abstract}

Keywords: Cyber crimes, Women, Harassment, Abuse, Violence, Awareness, Security, India.

\section{INTRODUCTION}

Today, if we ask anyone what could be an empowering tool and platform for women but at the same time can also be a platform for abuse and harassment? The obvious answer to this question will be internet and technology.

Violence against women, in general, is a topic that people avoid to discuss in the public or that it is not 'pleasant' conversation that one likes to talk. It is not discussed about in the name of so called, 'honor', and rather considered as a taboo. In such circumstances, online harassment is the 


\section{International Journal of Social Science and Economic Research}

ISSN: $2455-8834$

Volume: 05, Issue: 07 "July 2020"

even lesser known topic and the most vulnerable area because of the lack of appropriate knowledge about internet.

The increase of cyber crime is a global marvel. The security and protection of a person is at stake because of the advancement and the rapidity of the spread of technology. The advancement of technology has exploited the basic human rights in respect to women and poses a great threat to their security. India is one of the few countries to enact enactments to fight the increasing cyber crimes in the country. Women have been subjected to different kinds of harassment from time to time now, be it, abusive behavior at home, sati pratha, acid-attacks, rape, sexual harassment, honor-killing, female child murder and the list goes on. The list of the violence's has only raised and the kind of harassments has only been added to the list with the changing times. Currently, violence against women has taken a different turn because of the direct result of technology which is called as 'cyber violence', and this is the focal point of this paper. The rates of cyber violence against women in India are very high and these are only on the expansion (Geetha, 2011).

Cyber violence is a type of violence against women which is encouraged by the internet and information technology. Women, in general, are more prone to victimization over the internet than men and a large portion of them get sends from obscure men with filthy writings or substances, companion demands and so on which might be the after effect of information mining. The events of impersonation, passionate tricking, defrauding by creating cloned profiles in the social media are currently on the rise in India and less mindfulness also causes the cyber victimization. Now-a-days, the use of Cyber platforms has been particularly to harass and abuse women and children for voyeuristic pleasures in India. Women and children are mostly targeted for cyber stalking, harassment, extortion, blackmail, etc in India. About $75 \%$ of the victims of cyber crimes are accepted to be female however; these figures are more on expected premise. The actual figures can extremely never be known because of the fact that most crimes of such sorts go unreported having no a direct physical threat and are very little clear or actualized appropriately. This is the sole reason why cyber crimes against women are on the ascent.

In India, the usage of digital platforms gained the momentum in the last decade which has a huge impact on the women and children who are enrolled in it. The women often fall prey to the cybercrimes that emerge in the social media outlets. Although the internet is a relatively new phenomenon but it has been able to sweep the world in its sphere. There have been instances and increasing evidence that social media even influences suicide-related behavior in its extent of the crimes. India, at present, is witnessing a non-stop increase in the number of cyber crimes, especially against the women. The aim of the present study is to focus on the interconnection between the internet, technology, social media platforms and the crimes against women which 


\section{International Journal of Social Science and Economic Research}

ISSN: $2455-8834$

Volume: 05, Issue: 07 "July 2020"

has been on the lead in India. The study is based on secondary literature of articles, books, journals, reports and web search in the context of cyber crimes and cyber violence against women in India.

\section{Is the social media playing the 'demon' behind the screens against the women?}

In the past few years, social media has been fully developed and managed to spread like a wildfire across the globe engaging people from every nook and corner. Besides being educative, social media increases connections and communications by building bridges over barriers and strengthening relationships. If used properly, social media could be therapeutic, promoting community participation and boosting one's confidence and potential.

But, social media is a doubled edged sword having its perks and flaws. Although, in the present day scenario, it is more aligning towards the flaws rather than the perks.

In recent days, there has been tremendous rise of adolescents falling victim to behavioral changes caused by the overuse of social media and having internet addiction. Reports suggest that individuals engaging in social media during late night tend to experience anxiety and depression. The teenage boys and girls are so emotionally invested in their social media handles that they seek comfort amongst various strangers rather than their family. It has been also found that there is "clear association" between social websites and the occurrence of mental health problems. Lately, there has been terrific misuse of social media making the women and children fall prey to the nefarious designs of the cyber web who continues to trap more and more misguided Indian youths. Women and girls are more inclined to be bullied frequently and to be reported for showing symptoms of mental ill-health. The act of cyber bullying throws the victim into a box of depression and anxiety that mostly goes to the extent of committing suicide.

Cyber-crimes against women and children are on the raise and they have been drastically increasing in the cyberspace. Some accused try to defame women and children by sending obscene e-mails, stalking women and children by using chat rooms, websites etc., and developing pornographic videos mostly created without their permission, spoofing e-mails, morphing their images for pornographic content etc. Indian women are not able to or hesitant, in most cases to report the cybercrimes immediately. Most of the problems could be solved if women report the crime immediately and warns the abuser about taking stronger action.

The Indian Government passed the Information Technology Act (also known as ITA-2000, or the IT Act) on $17^{\text {th }}$ October, 2000 that primarily deals with cybercrimes and electronic commerce across India. Unfortunately, this law has failed to curb the increasing cybercrimes. 
Cyber Bullying is relatively common across the world but the effect of it amongst the adolescents in India differs because of the diversity in culture and ethnicity across. In the Indian context, cyber bullying is caused through nasty and fake information about another individual, posting, sending and sharing negative and harmful content causing public character assassination and humiliation. The most dangerous cyber bullying in India is triggering religious, racial, ethnic or political hate comments or messages to convey negative reaction.

Cyber bullying is done in different forms, for example:

- Hacking of accounts

- Stalking

- Humiliating content posted online about the victim

- Posting of vulgar messages

- Hacking of social media handles

- Child pornography etc.,

The effects of cyber bullying have long term effects that affect the mental well being of an individual. According to a survey conducted between 25 countries by Microsoft in 2012, India ranks at number 3 in the list of online bullying. About 70\% percent of cyber bullying activities happens in Facebook, Twitter and Instagram accordingly. The overuse of smart phone by $80 \%$ of teens in India makes them more of a victim to bullying. Young girls and women are more preferred victims of cyber bullying in comparison to boys. To top that, the victims of cyber bullying are 2 to 9 times more prone to committing suicide. The cases of cyber bullying of women or children has increased by 36\% from 542 in 2017 to 739 in 2018 (NCRB).Meanwhile, the conviction rates of cyber bullying of women and children fell by $15 \%$ points, to $25 \%$ in 2018 from $40 \%$ in 2017. 


\section{Figure-1}

Experience And Reporting Of Cyber Bullying (In \%)

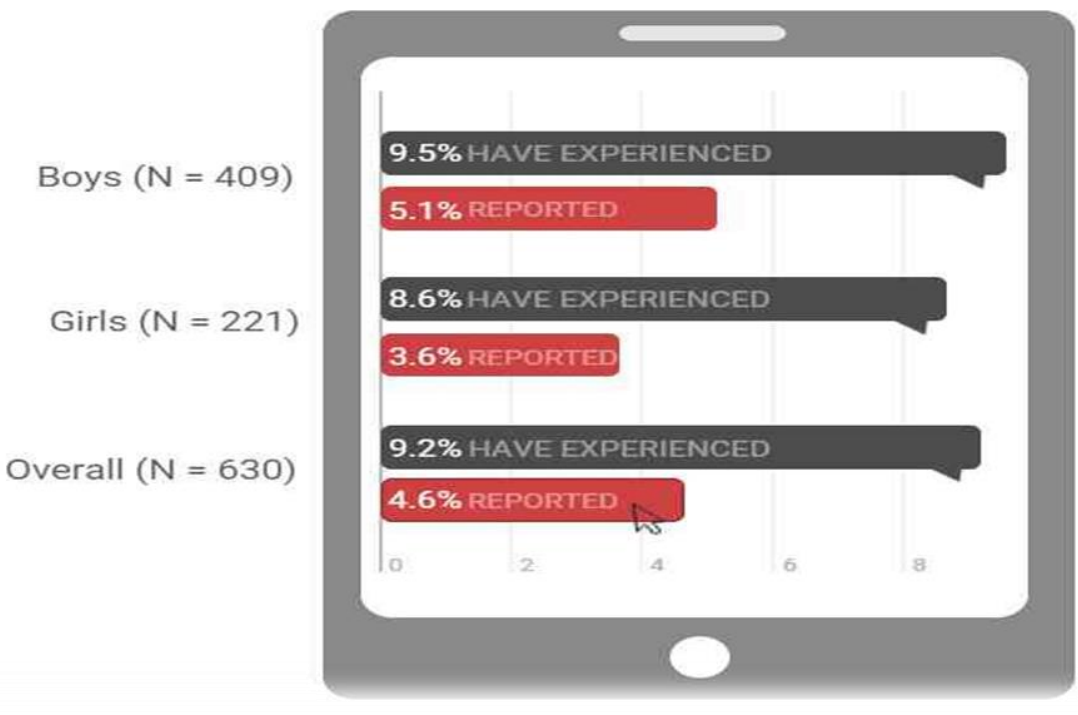

Source: Child Rights and You Study

The biggest problem in reporting cyber bullying is that a large number of the victims fail to recognize that what is happening to them is bullying (Nishant Shah, 2020). The prevalence of bullying has been fundamentally normalized in our digital space and as such, the victim remains unaware of the harassment and bullying that are being faced by them is not natural or normal and eventually lose their zeal to actually report and use the grievance to find justice. Many other reasons why cyber bullying is rarely reported because, the victim is often unaware of legal options, fear retaliation or stress about being stuck with defamation charges (Karnika Seth,2020).In other words, victim doubts the legal framework and unsure about the trained officers to investigate the crimes.

It is important that the police register a first information report when a cognizable is being reported. There have been many instances when the police didn't or refused to register the case at all. 


\section{Figure-2}

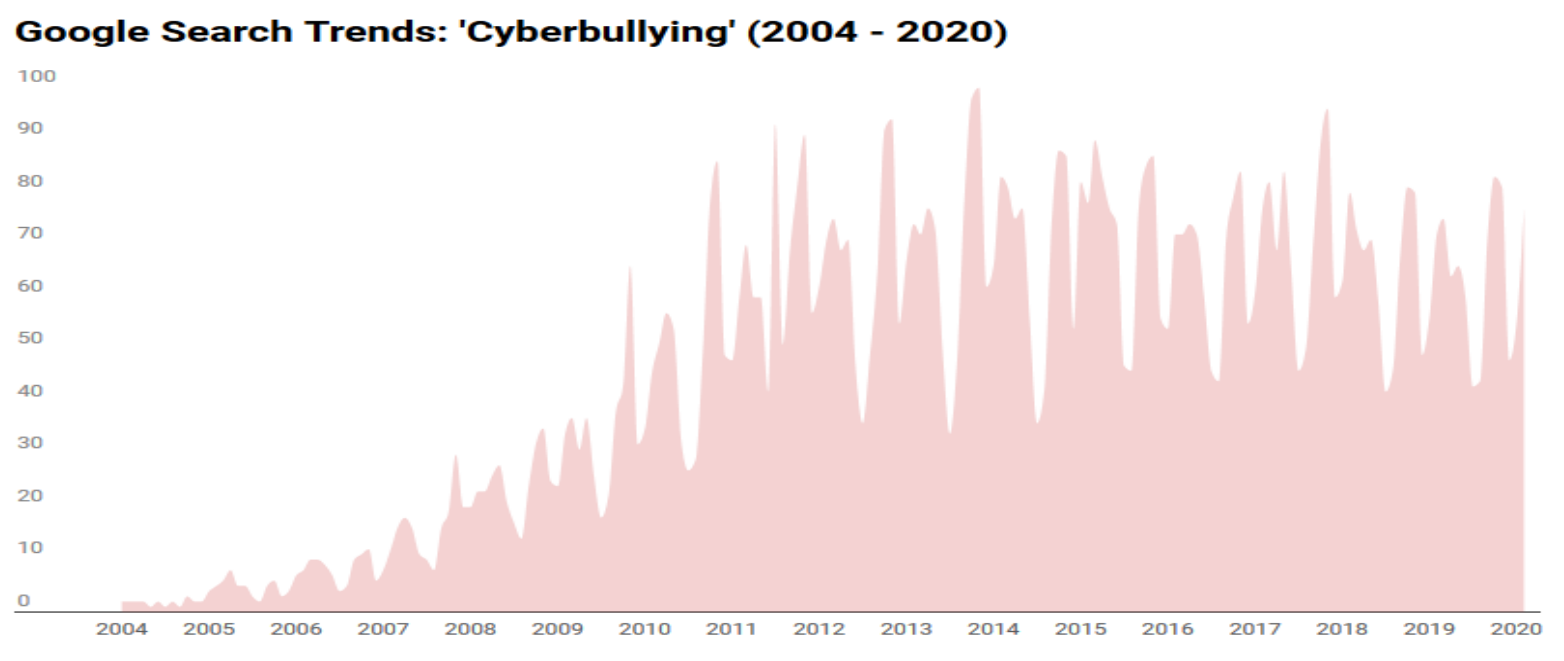

\section{Source: Google Trends}

In the event of growing cyber bullying cases in India, it is important to create awareness of the definite crime among women and children. Campaigns like conducting focused training programmes for the women on the vivid details of internet safety and guidelines could prove to be effective. The existing cyber laws needs to be revised for women safety issues, most necessarily, portals should be set up where cyber-crime can be reported.

Doxing or Doxxing is solely an internet-based practice whereby an individual's private information or personally identifiable information (like names, address, phone numbers, email address, photographs, relatives and much more) are leaked. This data about an individual is often pulled from social media websites, hacking and social engineering which is later released publicly against the person's wishes. Doxing is particularly performed for the purpose of blackmailing or seeking revenge by exposing the individual's vital information or out of general curiosity about the person. In both the cases, the victim is being mentally harassed and abused and tends to have serious consequences on their health, livelihood and relationship.

Any individual can be a victim of doxing. Mostly the victims of doxing are popular on social media and have a huge amount of followers. These include celebrities, vloggers, journalists and other social media influencers. The celebrities and politicians have always been targeted by hackers. Famus people like Michelle Obama, Al Gore, Hillary Clinton, Sarah Palin, Beyonce, Paris Hilton, Britney spears, etc. These high-profile victims are just a minor fraction of the long list of the targets whose personal information has been leaked online. 


\section{International Journal of Social Science and Economic Research}

ISSN: $2455-8834$

Volume: 05, Issue: 07 "July 2020"

Recently in India, a student of NIFT named, Akshara, was doxed because of her political opinions and for being a supporter of BJP. She shared a note in Twitter claiming,

"I was doxxed by someone from my college (NIFT) because of my political ideology. My phone number and my private info was first doxxed three months ago. My parents; I still remember were worried cause I have been therapy since more than a year now thought I might relapse and slip into depression and severe anxiety again. I had my personal issues that I had been dealing with. I never thought my political orientation would be leading me to be perplexed with anonymous threats. I filed several complaints against anonymous handles thinking somehow the torture would stop. It didn 't."'

After Akshara's plight gained momentum on social media, National Commission for Women chairperson Rekha Sharma, responded saying that she will look into the matter and resolve it right away.

Akshara was not the first person to fall prey to this harassment and definitely not the last. There are many cases such as Akshara's who goes unnoticed and unresolved making the victim vulnerable. It is to be noted that in India, particularly, harassment of private individuals are targeted due to their political inclinations and opinions and it has continued to prevail in the last few years. In an age where social media and digital presence is a crucial part of many people's professional lives, doxxing and online harassment brings disastrous consequences in the lives of the victims.

In India, there is no specific law in place to prevent or punish doxxing directly, but there are laws against Voyeurism (Section 354IPC and IT Act), obscene content (Section 292 IPC), online stalking (Section 354D IPC), divulging sexually explicit content (The IT Act) and defamation (Section 499 IPC).

The act of doxxing is entirely unethical and illegal under state criminal laws. It's a crime that can lead to serious legal consequences like imprisonment, if one is caught harassing others and sharing their private information without permission. In India, where there so limited laws for cyber crimes, doxxing doesn't really falls in the radar and more often law enforcement has difficulty in identifying and prosecuting these types of crimes. Doxxing particularly violates an individual's Right to Privacy (A Fundamental Right) and threatens one's Right to Dignity (Article 21 - Constitution of India) and subjects the individual to harassment and places the victim in a place of danger.

Internet Trolling is a person trying to quarrel or upset people on the internet by sending derogatory or inflammatory comments, which is very harmful, depressive and extraneous with the intent of provoking the victim into displaying the emotional response intended. We are 


\section{International Journal of Social Science and Economic Research}

ISSN: $2455-8834$

Volume: 05, Issue: 07 "July 2020"

gradually stepping into an era of trolls. Internet trolls disrupt the lives of many with sexist, racist, divisive, discriminatory and xenophobic content. Earlier, trolls used to work alone but there has been a growing trend of "troll armies" where several trolls coordinate and attack a single individual/organization under a single argument and attack the ones who disagrees with them. This growing trend of trolling and trolls have created a culture of fear among many where an individual is subjected to death threats, rape threats, half-truths, offensive language and psychological abuse.

In India, the trend of trolling has become a serious issue. With a social media population of over 50 million accounts on Whatsapp, 88 million in Instagram, nearly 200 million users in Facebook and 153 million in social media users, makes the users more prone to trolling in comparison to any other. According to a study conducted in 2014, almost 50\% of Indian youth have experienced bullying or have been involved in online bullying. Many teenagers and young adolescents in their way of trying to 'fit in' and act 'cool' often try or post dangerous things to get more attention, likes or shares. The report also stated that $20 \%$ of the cyber bullied teenagers think of committing suicide.

The victims of trolling are mostly between the age of 18-29 years, i.e, the teen girls and women. According to the data stated in Pew's Research first report on internet harassment (2014), it was found that $40 \%$ of internet users were personally subjected to online harassment, $73 \%$ of the ones witnessed it happening to others and about $24 \%$ of the users saw someone being harassed for a sustained period of time. Another study conducted by British think tank, Demos, it was found that men receive more abusive messages on social media, and men sends three-quarter of abusive messages. In the same survey, it was revealed that online abuse is comparatively higher in women than men. One in every four women between the ages of 18-24 have reported being stalked and sexually harassed online, a rate that is nearly three times higher than among men of the same age group.

In India, a lot of women have been facing the hard side of trolling due to the use of abusive language which is so bitter and harmful that they find it better to die rather than live with the echoes of such messages. The act of slut-shaming, body-shaming, catcalling, using sexually explicit terms, rape threats, threats of acid and death threats too are what women are mostly trolled and bullied with. The troll makers realize it now that character assassination is what breaks a woman into broken pieces.

A 19-year-old girl in India, who wished to maintain her anonymity, spoke to SheThePeople.tv about her horrific troll incident and the trauma that she has been carrying it till date. She says, 


\section{International Journal of Social Science and Economic Research}

ISSN: $2455-8834$

Volume: 05, Issue: 07 "July 2020"

"A classmate of mine liked me in school days and asked me out for a relationship. I was not interested and politely refused it. He was persistent but I denied every time. I distanced myself

hoping for the better but it backfired. An anonymous id (he) hacked and froze all my social media accounts. Various screenshots of different conversations and pictures were then posted on our school's trolling page. My name was mentioned in every post and the harshest of words were used. The kind of words led me to hurt myself physically. Till date, I have no social media account. I had to shift my school and locality and start afresh from the horrific impact of the words used for and against me."

Many women and girls fall victim to this trap of trolling whereby creating chaos and panic in their lives. The impact of trolling can be very adverse and push on an individual, especially a teen pushing them to take drastic steps in their lives.

In a recent study from Ipsos in, polled parents of 28 countries to determine the cyber bullying rates in 2018. It was found that nearly one in five parents worldwide claim that their child has experienced cyber bullying at least once. In India, the problem is particularly is very degrading as it has the highest rate of parents confirming to the incidents of cyber bullying with a total of $37 \%$ parents across India agreeing that their child was bullied online, and 14\% of that total say that the bullying occurred in a regular basis.

Figure-3

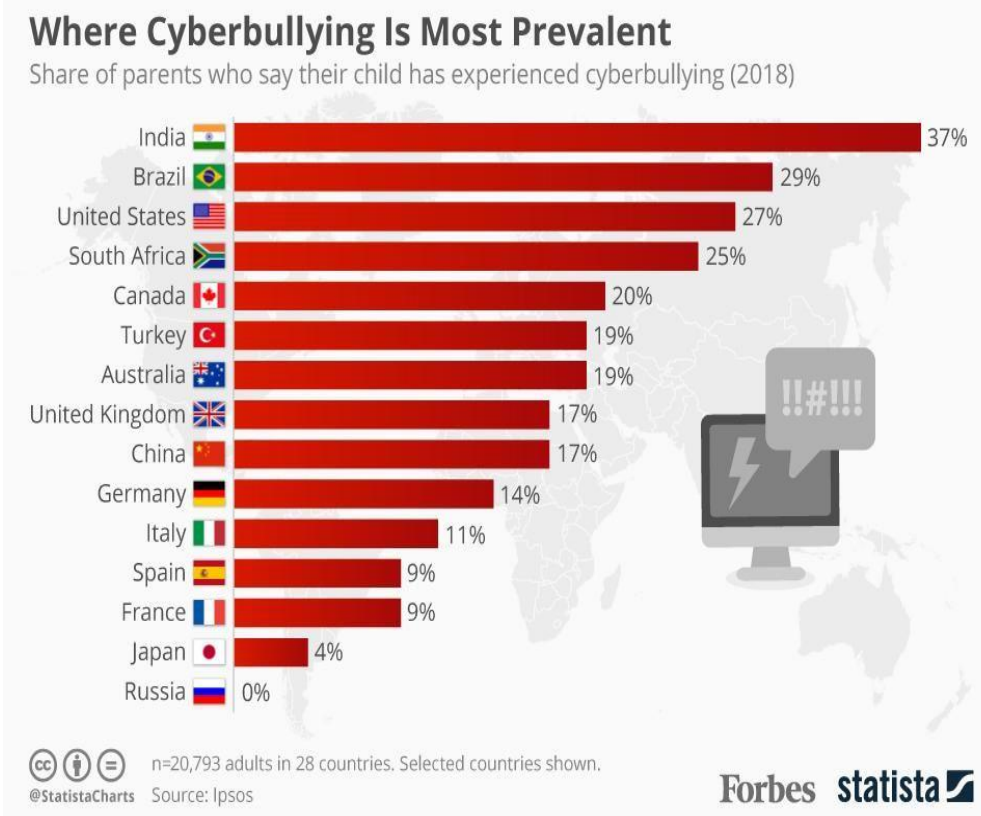

Source: Ipsos 


\section{International Journal of Social Science and Economic Research}

ISSN: $2455-8834$

Volume: 05, Issue: 07 "July 2020"

Although, trolling does a grave damage to an individual's mental state, yet there are no such laws against trolling as it will collide with the Act of Freedom of Speech in the Indian Constitution. Trolling is the basest form of speech or dialogue over the internet. It is very much contagious and inflammatory. As a sensible social media user and responsible citizen, our part would be not to resort to trolls or stoop down to their level as it is a mere matter of basic civility and basic human decency.

Cyber Stalking generally refers to repeated acts of harassment or threatening behavior of a cyber criminal towards the victim by various means of the internet services. Whether the stalking is online or offline, the stalker tends to have the desire to control the victim's life entirely.

The cyber stalker operate by collecting all the personal information about the victim (such as, name, family background, address of residence, place of work, DOB, etc). If the stalker happens to be an acquaintance, the access to details of the victim is quite easy. If the stalker is a stranger, he collects the required information from the internet sources through various profiles in the social media handle. The stalker operate by posting this private information on any random website related to sex-services, dating services, posing as if the victim is disclosing the information by providing telephone numbers or any other contact details. These acts of the stalker mentally harass the victim and creates disturbance in her life, by her private information being leaked out in the open.

Cyber stalking, at times go beyond monitoring, threats, vandalism, solicitation for sex, vandalism, collecting information to threaten or harassing the victims. These are often accompanied by offline and real-time stalking. One of the most used modes of cyber stalking is "Catfishing”. 'Catfishers' disguise themselves as someone else through social media sites and mostly aim for monetary gain, to victim as a romantic partner or a mutual friend of the victim and also cause harm to their reputation and humiliation to the victim. Some cyber stalkers go to the extent of hijacking the webcam of the victims and conning them into downloading and installing files that grants them access to their computer or laptop.

Cyber stalkers stalk or harass their victims for various reasons, varying some of them suffering from pathological infatuations, either sexual or professional, or some of them suffer from inferiority complex, or to threaten and instill fear, or to seek revenge over rejection, personal or professional reasons.

According to recent statistics, cyber victimization showed that the number of women victims outnumber the male victims in terms of cyber stalking. In a cumulative statistics released by Working to Halt Online Abuse (WHOA) dealing with cyber stalking, showed that 4043 victims who contacted WHOA in the years of 2000-2013, 70\% were women. In a recent report released 
by UN Broadband and Gender, too, showed that women from the age of 18-24 are at the high risk of being abused and harassed on the internet through cyber stalking (UN Report, 2015:16).

Until January 2013, there were no laws that recognized the legal definition of stalking or cyber stalking in India. In 2013, through S.35D of the Indian penal Code, stalking was legally recognized as an offense in India which was included through the Criminal Law Amendment Act, 2013. According to the provision,

"Any man who follows a woman or contacts or attempts to contact such woman to foster personal interaction repeatedly despite a clear indication of disinterest by such woman or whoever monitors the use by a woman of the internet, email or any other form of electronic communication or watches or spies a person in a manner that results in fear of violence or serious alarm or distress, in the mind of such woman or interferes with the mental peace of such woman, commits the offence of stalking."

With the increase and change in modes of cyber crimes, laws are constantly amended to keep up. However, there are no provisions in the criminal laws that specifically criminalize cyber stalking in India.

\section{Figure-4}

\section{Stalking Cases Double In 4 Years}

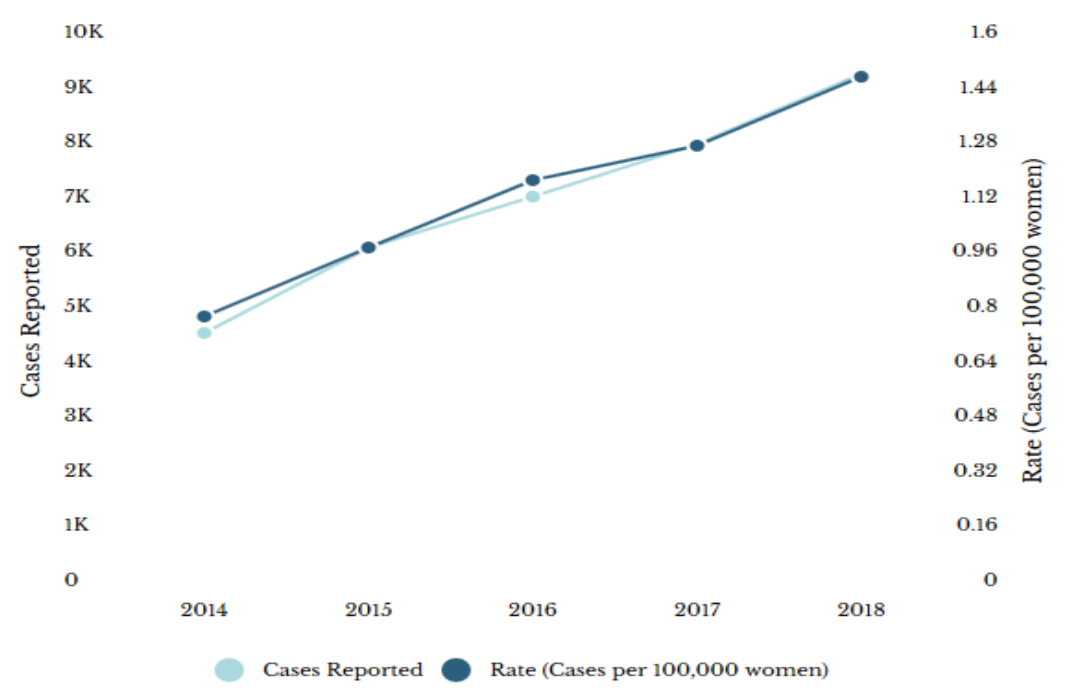

Source: Crime in India reports for the years 2014, 2015, 2016, 2017 and 2018, National Crime Record Bureau. 


\section{International Journal of Social Science and Economic Research}

ISSN: $2455-8834$

Volume: 05, Issue: 07 "July 2020"

With technology democratizing the social media eventually, India currently has now around one billion mobile subscribers, an estimate of 500 million Internet users. With the surge in mobile and internet subscribers, there has been an intense increase in cases of cyber stalking, especially among women. Initially, there was a certain profile of harassers mostly in the age group of 11-25 years, and educated. But, now more and more people are involved in the internet, even those who are not vey educated, but are only mobile-literate. This transformation is converging into a phenomenon of social media extortion.

In India, most of these cases go unreported, either by the police or by families or by the victim itself, because of the mere belief that these acts of harassment are regrettable but not really worth punishable. Cyber stalking in India is not covered by the existing cyber laws. It is covered only under the ambit of Section 72 of the IT Act that the perpetrator can be booked remotely for the breach of confidentiality and privacy. The accused may also be booked under Section 441 of the IPC for criminal trespass and Section 509 of the IPC again for outraging the modesty of women. Although, there are laws against online harassment are in place, implementation of these laws is where the problem actually is.

\section{Well, if she is avoiding me, then I must definitely teach her a lesson!}

In June, 2014, a 17-year old school girl fell victim to cyber bullying in Kolkata and committed suicide, the night after her friend uploaded a morphed picture of her in a social networking site. The victim left a six page suicide note that formed the basis of the entire incident.

Police sources said that the girl befriended a boy named, Faisal- a 23 year old student, on a social networking site couple of months ago and quickly became close friends. But, after some time, she started avoiding Faisal and thus with the intention of seeking revenge, Faisal decided to defame the girl in public. For this purpose he roped in two of his friends, Deepak and Satish and together they created a fake profile of the girl. In that profile, morphed pictures of the girl were uploaded along with her phone number, saying she is "seeking friends" and "open to relationships". After this, the girl started getting obscene phone calls and she realized that she was trapped. Finding no alternative, the girl decided to kill herself.

In her suicide note, she firmly alleges that she was forced to kill herself after being defamed at social networking sites.

After the incident, the police pleaded the ones suffering from cyber bullying to immediately contact the local police and they will help them with a legal counsel and get the fake profiles deleted. 


\section{International Journal of Social Science and Economic Research}

ISSN: $2455-8834$

Volume: 05, Issue: 07 "July 2020"

The life of such a young girl was taken away because she needed to learn a lesson and not do what she actually wants. The above incident is just the tip of the iceberg. There are innumerous cases taking place in India where women are subjected to this kind of harassment and abuse. Women are mainly looked as in the soft target for harassment and thus they turn out to be the most vulnerable of these cyber crimes.

Indian women are still not open to immediately report the cyber abuse and cyber crime that they face which is the biggest problem. This hesitant behavior of the women provides the offenders the chance to escape after the commission of the crime. Although many websites and blogs provide security tips for the safety of women and children in the internet but still cyber crime against women and children are on rise.

\section{I kept telling but no one heard me. Why should I live?}

In June 2016, the Tamil Nadu Police arrested a man for allegedly uploading a morphed picture of a 21-year old woman in Facebook. The woman, was identifies as Vinupriya, who committed suicide after her morphed picture went viral. The victim's family demanded immediate arrest of the culprits behind the cyber crime.

Days before the incident, a complaint was lodged with the police but no action was taken, according to the victim's father, who said that another semi-nude picture of Vinupriya was sent to her father on his mobile following which she took the extreme step. The victim's father held the police responsible for his daughter's death because the action wasn't taken at time.

Several cases like Vinupriya, the police many a times don't register the cases because they remain unsure if they would be able to crack it. The police sems to be more comfortable with the traditional laws related to the crimes that happen physically. There is no proper capacity building among the law enforcement agencies. Thus, majority of these cases in India fail to be proved guilty.

Social media has become more of a platform for shaming and putting people down. It is like being taunted and mocked in the middle of a public road by a man, except people on a public aren't continuously posted or criticized while, online is a continuous space of scrutiny. The fact and the thought that once a picture is leaked, it will stay there, even if you get it removed, there will be someone with a screenshot of it. In cases like of, Vinupriya, the burden of shame was unbearable, especially without any support structures. The victim felt it as an incredible burden.

Kavita Krishnan, activist and secretary of All India Progressive Women Association, says, "Patriarchy enables you to put down a woman in a way you cannot do to a man. The fact that 
International Journal of Social Science and Economic Research

ISSN: $2455-8834$

Volume: 05, Issue: 07 "July 2020"

she or any other woman had to be concerned about what people will say, how they will brand her as immoral, is not something that men have to deal with."

The impact of online harassment and abuse is same, but no less than the harassment in the physical world, but it is our mindset that is not equipped enough to recognize it. When an individual is someone is defamed and harassed online, it is viewed by a much larger audience and the victim feels helpless about not being able to contain the spread of the information or a photograph. The sense of trauma, shame and the feeling of being ripped away from privacy and being exposed are so much higher.

The accused in the Vinupriya case removed the obscene picture from Facebook and was arrested and he confessed to the crime. Although, Vinupriya is not there to tell her side of the story but the note that she left, revealed the brutality of the internet that, many others fall victim to it like her every day.

\section{Are the women being predicted as the soft target at the internet?}

The growth of Information Technology in India has taken a quantum leap since 1990s and is still continuing strong. Every other household with moderate economic condition have access to internet now. India has over 560 million internet users, making India the second largest online market in India, after China. In 2019, India had around 525.3 million internet users and it is estimated to grow over 660 million users. In other words, internet has brought the world into our living rooms. Today, people from the age group of 13-70 years has access to the intenet either from their home, work, cyber places, or at educational institutions, etc.(Halder \& Jaishankar, 2010:1). So, it can be said that the internet has exposed the society to a new world of ideas, culture, values and opportunities.

But, unfortunately the internet too is not a safe space for women anymore. Out of the total internet users in India, 30\% of it comprises of women who becomes the most vulnerable targets on the internet. Cyber space has now become an instrument for offenders to victimize and infringe the women. Internet as a result, has opened the gates for various crimes against women in the cyber space. Although, various draftsmen and world leaders participate in the EU conventions to establish strict rules to contain the cyber crime rates against children, never really considered victimization of women in the cyber space as an issue like child pornography, o hacking etc. which require the most important attention (Halder \& Jaishankar, 2009:5-6). There is no denying the fact that, the coming of the internet has made life easier for all, including women across the world, but along with it, it has also led the rise in the crimes of internet against 


\section{International Journal of Social Science and Economic Research}

ISSN: $2455-8834$

Volume: 05, Issue: 07 "July 2020"

women. Cheekay Cinco of the Association for Progressive Communications says that, "Violence against women is mutating because of technology (Manila, 2011)."

Regarding the cyber crimes, women remain to stay ignorant of these crimes and their inherent danger. In 2016, a nude video clip of Radhika Apte, a Bollywood actress, shot for an international film was leaked in the internet. The director of the movie, Anurag Kashyap had to register a case against the unknown person with the cyber crime cell of Mumbai Police. In 2013, Mona Singh, an Indian TV actress was a victim to a leaked MMS clip that allegedly featured her. The video went viral overnight. The actor had to issue a statement confirming that her face was morphed in the video. She even filed a complaint but the perpetrators were not found. To be said, women from every corner of the country have been subjected to cyber crime and yet many of them remain to stay unaware about it. It is only when they come to know about the truth, it gets too late by then (Geetha, 2011). Thus, the internet has become a play ground for fraudulent people who try to harass and abuse women.

Statistics also show that cyber awareness among people in India is very low.

\section{Figure- 5}

\begin{tabular}{|l|l|l|}
\hline Awareness of cyber culture among Indian internet users & Yes & No \\
\hline $\begin{array}{l}\text { 1. Knowledge of minimum age to join cyber communities like } \\
\text { Facebook, Orkut, Myspace etc }\end{array}$ & $56.2 \%$ & $43.8 \%$ \\
\hline $\begin{array}{l}\text { 2. Allow others to use one's own email id / profile id /passwords } \\
\text { etc }\end{array}$ & $46.6 \%$ & $53.4 \%$ \\
\hline $\begin{array}{l}\text { 3. Use safety tips like filtering emails, locking personal albums } \\
\text { and information, personal walls of social networking sites etc; }\end{array}$ & $69.9 \%$ & $30.1 \%$ \\
\hline $\begin{array}{l}\text { 4. Mail back to unknown senders of spam / pornographic / erotic } \\
\text { /phishing mails }\end{array}$ & $37.0 \%$ & $63.0 \%$ \\
\hline $\begin{array}{l}\text { 5. Share personal information / emotions with virtual friends / } \\
\text { chat room partners etc whom you don't know in real life }\end{array}$ & $74.0 \%$ & $26.0 \%$ \\
\hline $\begin{array}{l}\text { 6. Believe in controlling free speech while communicating in the } \\
\text { cyber space }\end{array}$ & $37.0 \%$ & $63.0 \%$ \\
\hline 7. Read policy guidelines of social networking sites, ISPs etc; & $28.8 \%$ & $71.1 \%$ \\
\hline 8. Use pseudo names & $45.2 \%$ & $54.8 \%$ \\
\hline
\end{tabular}

Source: Cyber Crime against Women, 2014

There is no surprise to the fact that cyber crimes are easy to commit with very little resources, but the damage could be huge to the security of women. The internet technology came into existence only in 1986, but it has shown unparallel aggressive growth since then. It was 16 years 


\section{International Journal of Social Science and Economic Research}

ISSN: $2455-8834$

Volume: 05, Issue: 07 "July 2020"

before 50 million people used a personal computer. Once the internet was made available to the general public, it took only four years for 50 million people to go online (Prashar, 2004). Thus, the internet has seen unparallel growth along with it; it has been posing a great threat to women security.

\section{The Key Findings of the Study:}

1. The women and children related cyber crimes and cyber harassment remain intensely underreported due to the stigma associated of 'What will people say and think?' a phrase every Indian woman is familiar with. The preference of parents/guardians to not involve police in such matters and not realizing the depth of the matter.

2. Majority of people don't feel the need to read the guidelines and policies, terms and conditions before signing up at these sites and thereby opening accounts.

3. The people engaging in virtual socializing are not aware of spam or phishing emails, etc. and of the basic cyber ethics.

4. The process of reporting for cyber crimes needs to be simplified and should ensure the involved women and children that these crimes would not go unreported. It is extremely necessary to simplify and strengthen the cyber crime investigation involving women and children so they, don't have to think twice before reporting any such incident.

5. The many cyber laws have not been formulated properly and the procedure for registering a complaint is not known by a woman, especially the ones hailing from rural and remote areas.

6. Social media handles in Facebook, Instagram, Twitter, etc., are the most common spaces where the women are subjected to harassment and many fail to understand the real nature of cyber stalking. It was found that many are aware that cyber crimes can invite legal problems but maximum internet users are not aware of the fact that cyber stalking can also invite penal actions.

7. Although there have been a prolific increase in online harassment of women and child sex abuse in India, but National Crime Records Bureau (NCRB) of India does not maintain any separate data or record of cyber crimes against children and women.

8. The data existed in NCRB currently is quite simple and the data shows extremely deprived law enforcement regarding these crimes as it only caters the information of reported cases and fails to throw light on the true occurrence rate of such crimes.

9. With time, there has only been an increase in women harassment and exploitation in the cyber space with the advanced and updated technology and anonymity. It takes an ample amount of time for investigation and many a times cases remain unresolved due to the lack of Cyber Forensics Laboratory. 


\section{International Journal of Social Science and Economic Research}

ISSN: $2455-8834$

Volume: 05, Issue: 07 "July 2020"

10. Currently there is no Digital Police Portal for women and children facing abuse and harassment on the online platform.

11. The legal system in India is failing to define the cyber laws which are one of the main reasons for the increase of cyber crimes. There is a dire need to use law as an instrument of change and thus, the law makers should put more focus upon substantive equality. Just like trolling should be well defined, the scope of the cyber laws must be widened.

\section{CONCLUSION}

While concluding, it comes to the visibility and attention that cyber crimes against women are very challenging. When it comes to cyber crimes in India, it is still taken lightly and don't receive the kind of importance it should, mostly because in general, the respect towards women in our society is constantly degrading and a lot of the accused people fail to come in terms with the fact that even posting pictures of someone online without their authority is a crime. Cyber crimes like pornography, morphing, defaming, etc, don't receive a moral backing in the society as it should and thus it is taken very casually. It is very essential for people to realize as to where social advancements are needed, and where people needs to recognize the rights of others and realize what exactly constitutes as a crime.

However, the actions of the Government too needs to be strengthen in order to deal with the cyber crimes because criminals find it easier to get away from committing cyber crimes because of the lesser chances of being caught and fewer penalties. When Indian laws neglect the changing situations of the cyber space, the approaching emergency to be looked by different nations must be envisioned. Cyber victimization of women is a piece of the image, yet managing first hand and on need premise with this image can complete a lot of aiding and lessening cyber crimes. The effort to defeat the cyber crimes against women all in all is testing and the main route is to understand cyber crimes.

Lastly, women too should need to take an interest in such activities and start breaking their silence and come forward for fighting against every cyber crime and the norms associated with it. The perception and mindset of the people should be changed and persuade them to develop a sense of commonality because the change first begins at home.

\section{REFERENCES}

Ghorai. S., Thapak. N.K. (2018). Cyber Crime, Victimization against Women in India and its Preventive Measures. Ignited Minds Journal.

Sankhwar. S., Chaturvedi. A. (2018). Woman Harassment in Digital Space in India. International Journal of Pure and Applied Mathematics. 
Singh. J. (2015). Violence against women in Cyber World: A special reference to India. International Research of Advanced Research in Management and Social Sciences.

Misra. R. (2014). Cyber Crime against Women.

Lohia. R. Cyber Stalking in India.

Balakrishnan. A. Cyber Stalking: Challenges In Regulating Cyber stalking at the Cyber Space.

Murali. J. (2020). Cyber Stalking: Get safe online.

Poulpunitha.S. Manimekelai. K., Veeramani. P. (2020). Strategies to Prevent and Control of Cyber crime against Women and Girls. International Journal of Innovative Technology and Exploring Engineering.

Aggarwal. V. S. (2018). Cyber Crime Victims: A Comprehensive Study. International Journal of Creative Research Thoughts.

Pawar. M. U., Sakure. A. (2019). Cyberspace and Women: A Research. International Journal of Engineering and Advanced Technology.

Uma. S. (2017). Outlawing Cyber Crimes against Women in India.

Chiluvuri. S. (2017). Cyber Savagery against Women - Present Scenario. GLOBAL JOURNAL FOR RESEARCH ANALYSIS. 